\title{
Photosynthetic Characterization and Response to Drought and Temperature in Wild Asparagus (Asparagus acutifolius L.)
}

\author{
Dario Mantovani and Adolfo Rosati ${ }^{1}$ \\ CREA Research Centre for Olive, Citrus and Tree Fruit, via Nursina 2, 06049 \\ Spoleto (PG) Italy
}

\section{Domenico Perrone \\ CREA Research Centre for Plant Protection and Certification, via Strada Statale 18, N 204, 84091 Battipaglia (SA), Italy}

Additional index words. gas exchange, $\mathrm{CO}_{2}$ assimilation, photosynthesis, ecophysiologic plasticity, thermal stress

\begin{abstract}
The wild asparagus species Asparagus acutifolius $\mathbf{L}$. is widespread in Mediterranean and subtropical environments, where its spears are consumed regularly. The species is known to have ecophysiologic plasticity, however there is no literature on this subject. This work aimed at assessing the photosynthetic characteristics of this wild species of asparagus, grown under full light (FL) and partial (i.e., about $40 \%$ ) light (PL) conditions, and evaluating its ecophysiologic response to drought and temperature stress. The photosynthetic response to light of spears and of new cladodes (NC; current year) and old cladodes (OC; previous year) was measured using an infrared gas analyzer coupled with a climatized cuvette chamber. Cladodes net photosynthesis at high irradiance was also measured at varying air temperatures and decreasing soil water availability. Results indicate that developing spears were photosynthetically active with no difference between FL and PL treatments. Photosynthetic rates did not differ between NCs and OCs and were greater for FL cladodes, except at low irradiance. Well-watered plants were photosynthetically active from 0 to $45^{\circ} \mathrm{C}$, with a maximum photosynthetic rate of up to $9 \mu \mathrm{mol} \cdot \mathrm{m}^{-2} \cdot \mathrm{s}^{-1}$ at $30^{\circ} \mathrm{C}$ and a decrease of about $60 \%$ at $45{ }^{\circ} \mathrm{C}$. The species also demonstrated high tolerance to drought, with positive net photosynthesis even at predawn leaf water potential values of $-2.4 \mathrm{MPa}$. Showing great ecophysiologic plasticity, this wild asparagus could be an interesting species in areas were conventional crop species are not profitable economically, or as an intercrop in agroforestry systems.
\end{abstract}

As a result of the intensification of adverse and extreme climatic events, there is a growing interest in the implementation of agrobiodiversity strategies and in alternative crops, characterized by low-input requirements and high tolerance to abiotic stress. Moreover, in developed countries, new and niche products often have good markets. One such crop is a wild asparagus species (Asparagus acutifolius L.), a perennial herbaceous plant with spears that have been used in the Mediterranean area as a delicacy food since ancient times (Aliotta et al., 2004). These spears are still appreciated and sold regularly in niche markets (Di Maro et al., 2013; Ferrara et al., 2011; Pieroni et al., 2005). This species is widely distributed in semidry areas and as understory vegetation (Conversa and Elia, 2009), showing high phenotypical plasticity with its ability to grow in both sunny or semishaded areas and also under

Received for publication 11 Feb. 2019. Accepted for publication 6 Mar. 2019.

We thank Dr. Darcy Gordon for language editing. ${ }^{1}$ Corresponding author. E-mail: adolfo.rosati@ crea.gov.it.

et al., 2019). Nonetheless, this wild asparagus has not been cultivated until recently, and the market is sustained mostly by harvesting spears from naturally occurring plants, so the price can be four times greater than that of the spears of the cultivated species Asparagus officinalis L. (Benincasa et al., 2007; Rosati, 2001). The high price makes it an attractive potential new crop, even though its yield is relatively less compared with the commercial species (Benincasa et al., 2007; Rosati et al., 2005). Being a relatively undemanding plant, this wild asparagus could be a suitable crop for low-input agricultural systems. In fact, considering that there are no selected cultivars and the plant is wild, the crop is essentially free of pests and diseases, and is suitable for organic farming. However, although some previous research investigated seed germination and transplant management (Conversa and Elia, 2009; Rosati and Falavigna, 2000) and cultivation techniques
(Benincasa et al., 2007; Rosati et al., 2005), no information is available on the photosynthetic traits of this species, nor on its tolerance to abiotic stresses. Such information would be useful to define crop potential and customize suitable cropping systems. In fact, as an evergreen species, it has advantages over the cultivated species, which is deciduous and therefore photosynthetically inactive for about half the year. The evergreen trait could make this wild asparagus suitable as an understory crop under deciduous tree species, which transmit most of the incoming radiation at ground level, from leaf fall to sprouting in spring. In addition, in the summer, drought may become a more severe limiting factor than light, and it is possible that under nonirrigated conditions, the most likely situation for this potential crop, some tree shade may prove beneficial, alleviating water and/ or temperature stress. This could explain the natural occurrence of this species under light shade, at forest margins, and in abandoned orchards and olive fields. However, to understand these mechanisms to optimize the cultivation of this potential crop, the photosynthetic characteristics of the species under different light environments, and different temperature and water stress, need to be known. Understanding the physiologic adaptation to drought and temperature stress is critical for land-use planning because of the intertwined relation between abiotic stress and primary production (Mantovani et al., 2014a, 2014b; Pearcy et al., 2012; Veste and Kriebitzsch, 2013). In our study, we evaluated the photosynthetic response of this wild asparagus species to varying temperature and water stress levels. More specifically, we investigated the photosynthetic response to temperature and water stress of different plant organs (i.e., spears, current- and previousyear cladodes), for plants grown and acclimated to either full light (FL) or partial shade. We also investigated morphologic traits associated with the plant's adaptation to different light environments.

\section{Materials and Methods}

Plant material. At the beginning of the experiment (June 2014), 20 two-year-old potted plants of wild asparagus (2-L pots) were transplanted into 9-L pots. Plants were obtained from seeds collected in the wild from many different individual female plants from different locations in the Umbria region (Central Italy). Half of the plants $(n=10)$ were exposed to FL, whereas the other 10 plants were kept, for the duration of the experiments (2014-15), under a shadecloth transmitting $40 \%$ of incident photosynthetic active radiation $(P A R)$, thus receiving partial light (PL). This shade treatment was chosen to simulate plant acclimation to shaded understory environments. Both treatments were well watered and properly fertilized throughout the whole experiment, except for the drought experiment described later. No pest and disease problems were detected during the experiment. 
Photosynthetic activity of different organs. During Spring 2015, the photosynthetic response to varying $P A R$ levels of the FL and PL plants was measured on different plant organs: 1) spear tips, about the top $30 \mathrm{~mm}$;) spear trunks (spear subapical portions), measured at $\approx 100 \mathrm{~mm}$ from the tip; 3 ) new fully developed cladodes (NCs) grown during the vegetation period of 2015; and 4) old cladodes (OCs) of shoots grown the previous year (vegetation period, 2014). Measurements were carried out using a portable infrared gas analyzer (model 6400; LICOR, Lincoln, NE) equipped with $\mathrm{CO}_{2}$ and light control modules. The measurements on NCs and OCs were performed by sealing small branches with $\approx 40$ to 70 cladodes into a climate-controlled leaf chamber $(30 \times$ $20 \mathrm{~mm}$ ). Two branches (one for OCs and one for NCs) per plant on each of the 10 plants per light treatment were measured. The total lateral area of the cladodes for each measurement was estimated by measuring length and diameter of 10 cladodes for each branch, approximating the cladode shape to a cylinder. The average lateral area obtained from the 10 cladodes was multiplied by the total number of cladodes sealed into the chamber. Because it is assumed that only one side of the cladode is sunlit, the photosynthesis values referred to half the lateral area, in accordance with the methodology used for Asparagus officinalis (Guo et al., 2002). Spear photosynthesis was measured by enclosing the spear tip or trunk into the leaf chamber. The lateral area was calculated by approximating the spear to a cylinder, and photosynthesis values referred to half the lateral area, assuming only half was sunlit. One spear tip and trunk per plant on each of the 10 plants per light treatment (i.e., FL and PL) were measured.

For both spear and cladode light response curves, air temperature in the leaf chamber was set at $20{ }^{\circ} \mathrm{C}$ and relative air humidity at $\approx 50 \%$. PAR intensity steps were as follows: $0,20,50,100,300,500,700,1000,1300$, 1500 , and $2000 \mu \mathrm{mol} \cdot \mathrm{m}^{-2} \cdot \mathrm{s}^{-1}$, and at each step the measurements were taken when steadystate assimilation was reached.

The morphology of the cladodes grown under the different light conditions (i.e., FL and PL) was evaluated by measuring cladode diameter and length, and calculating their lateral area, volume, and the lateral area-tovolume ratio for all the samples taken for gas exchange measurements $(\mathrm{n}=400)$.

Photosynthetic response to drought and temperature, and water potential. In addition to the light response curves, the photosynthetic response of NCs to varying temperature was evaluated on well-watered plants during Summer 2015 and the following winter at a constant PAR intensity of $1500 \mu \mathrm{mol} \cdot \mathrm{m}^{-2} \cdot \mathrm{s}^{-1}$ [net $\mathrm{CO}_{2}$ assimilation response $\left(\mathrm{An}_{1500}\right)$ ]. These additional measurements were taken on one branch (with the same characteristics as for the other measurements) per plant on five plants per light treatment at intervals of $5{ }^{\circ} \mathrm{C}$, from 20 to $45{ }^{\circ} \mathrm{C}$ during Summer 2015, and from 0 to $15{ }^{\circ} \mathrm{C}$ during the following winter.
In an additional experiment, during Summer 2015, the combined effects of drought and high temperature on cladode photosynthesis was evaluated by measuring the photosynthetic response to increasing temperature also at progressively reduced soil water availability. To impose drought stress, five potted plants per light treatment were not irrigated for 6 consecutive days. The level of drought was assessed by recording both the gravimetric soil water content $(\theta)$ of each pot and the predawn leaf water potential $\left(\Psi_{\mathrm{L}}\right)$ on days $0,2,4,5$, and 6 of the drought cycle. At the beginning of the experiment, the plants were overwatered, drained overnight, and pot weight was recorded, assuming the soil was at field capacity. The water-holding capacity of the soil was measured by using the thermogravimetric method (Pansu and Gautheyrou, 2007) on five pots without plants. From these measurements, we determined that field capacity corresponded to a $\theta$ value of $0.33 \mathrm{~kg} \cdot \mathrm{kg}^{-1}$. During the drying process, all pots were weighed in the early morning, and the $\theta$ values were calculated based on the weight difference compared with field capacity.

$\Psi_{\mathrm{L}}$ was measured on three small branches (like those sampled the for gas exchange measurement) per plant, on each of the five plants per light treatment, using a Scholander pressure chamber (Scholander et al., 1965).

The photosynthetic response to increasing temperature was assessed at field capacity $\left(\Psi_{\mathrm{L}}=-0.9 \mathrm{MPa}\right.$, day 0$)$, mild water stress $\left(\Psi_{\mathrm{L}}=-1.4 \mathrm{MPa}\right.$, day 4$)$, and severe water stress $\left(\Psi_{\mathrm{L}}=-2.4 \mathrm{MPa}\right.$ day 6$)$, sampling three branches per plant on each of the five plants per light treatment. The increasing temperature treatments were interrupted whenever net photosynthesis approached zero.

Data analysis. Data from different plant portions (spear tips, spear trunks, NCs, OCs) and light treatments (FL, PL) and from NCs at different temperatures and soil water availability were subjected to analysis of variance according to a completely randomized de- sign, with pots as replicates. Means were compared by least significant difference at the 0.05 confidence level. The $\mathrm{R}$ statistical environment ( $\mathrm{R}$ Development Core Team, 2014) was used to perform the analysis.

\section{Results}

Photosynthesis and morphology of the different organs. Light treatments had no significant effects on spear gas exchange (data not shown), therefore the data were pooled for the two treatments. The spear trunk (subapical portion of the spear) had negative net photosynthesis (An), but reached values close to zero when An saturated at about $1500 \mu \mathrm{mol} \cdot \mathrm{m}^{-2} \cdot \mathrm{s}^{-1}$ (Fig. 1A). The spear tips also saturated at similar irradiance levels, but had much more negative photosynthetic values at any $P A R$ tested, resulting from a 3fold greater respiration rate in the dark as shown by the An value at zero PAR. However, the spear tips photosynthetic contribution was much greater in absolute terms, as shown by the much greater values of gross photosynthesis (Ag) at any $P A R$ level (Fig. 1B).

NCs and OCs within the same light treatment had comparable An (data not shown), hence data were pooled. Cladode An increased with increasing $P A R$, never reaching saturation, in both light treatments (Fig. 2A). The FL treatment had greater An at $P A R$ values greater than $50 \mu \mathrm{mol} \cdot \mathrm{m}^{-2} \cdot \mathrm{s}^{-1}$, but An tended to be lower below this $P A R$ value, although not significantly (Fig. 2B). The light compensation point was reached at $P A R$ values of $18.5 \pm 4.0$ and $13.3 \pm 3.1$ $\mu \mathrm{mol} \cdot \mathrm{m}^{-2} \cdot \mathrm{s}^{-1}$ for $\mathrm{FL}$ and $\mathrm{PL}$, respectively. The FL plants had shorter and thicker cladodes with a smaller lateral area, and a smaller lateral area-to-volume ratio, compared with the PL plants (Table 1).

Photosynthetic response to drought and temperature. On day 0 of the drought experiment, pots were at field capacity $(\theta=0.33$ $\mathrm{kg} \cdot \mathrm{kg}^{-1}$ ) and the plants' $\Psi_{\mathrm{L}}$ was $-0.9 \mathrm{MPa}$
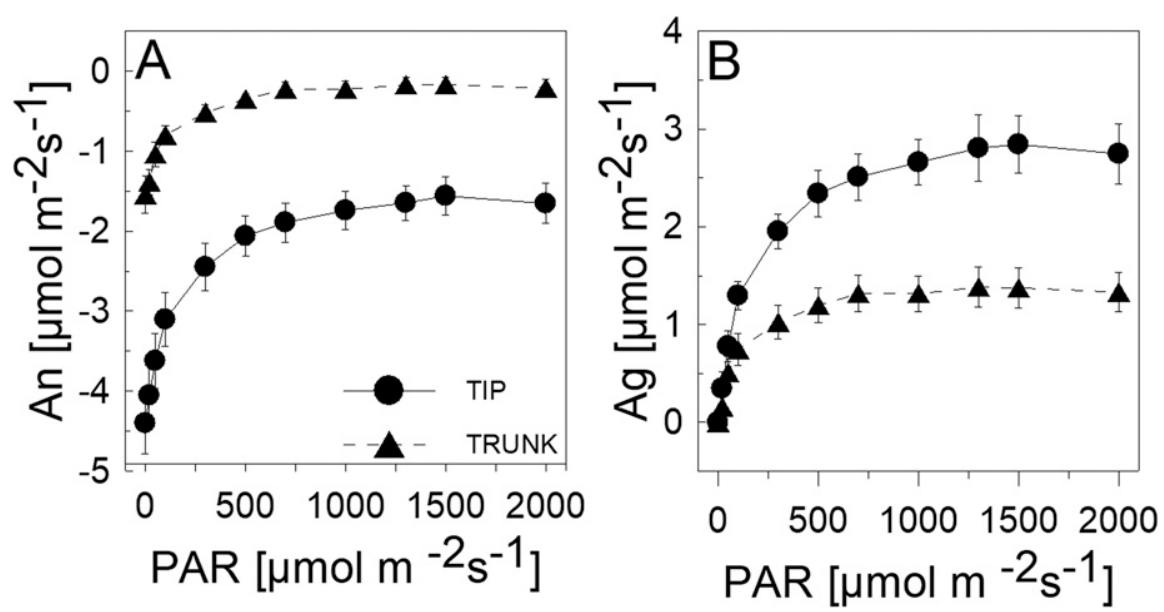

Fig. 1. (A) Net (An) and (B) gross $(\mathrm{Ag}) \mathrm{CO}_{2}$ assimilation response to photosynthetically active radiation $(P A R)$ of well-watered Asparagus acutifolius spear tips and spear trunks measured at $20{ }^{\circ} \mathrm{C}$ (air temperature). Data from the full light and partial light treatments were pooled. Data represent mean and SE (bars) of 20 measurements. 
(Fig. 3). As $\theta$ decreased, $\Psi_{\mathrm{L}}$ also dropped, reaching $-2.4 \mathrm{MPa}$ on day 6 , when $\theta$ was 0.10 $\mathrm{kg} \cdot \mathrm{kg}^{-1}$. With the soil at field capacity and with an incident $P A R$ of $1500 \mu \mathrm{mol} \cdot \mathrm{m}^{-2} \cdot \mathrm{s}^{-1}$, although the difference was not significant at any given temperature, $\mathrm{An}_{1500}$ was constantly greater for FL cladodes, except at extreme temperatures (Fig. 4A). The greatest photosynthetic rate occurred at an air temperature of $30{ }^{\circ} \mathrm{C}$ for both treatments, whereas at both higher and lower temperature, the difference between FL and PL declined dramatically, reaching zero at 0 and $45^{\circ} \mathrm{C}$. With increasing drought intensity, the difference in $\mathrm{An}_{1500}$ between the FL and PL treatments became negligible at any temperature, and data were pooled (Fig. 4B). $A_{1500}$ decreased with temperature at any drought (i.e., $\Psi_{\mathrm{L}}$ ) level and with $\Psi_{\mathrm{L}}$ at any temperature. At $30{ }^{\circ} \mathrm{C}, \mathrm{An}_{1500}$ was reduced by $59 \%$ and $83 \%$, respectively, with $\Psi_{\mathrm{L}}$ values of -1.4 and $-2.4 \mathrm{MPa}$. When the air temperature was increased from 30 to $35{ }^{\circ} \mathrm{C}, \mathrm{An}_{1500}$ decreased by $5 \%$ at field capacity $\left(\Psi_{\mathrm{L}}=-0.9 \mathrm{MPa}\right)$, by $74 \%$ under mild drought $\left(\Psi_{\mathrm{L}}=-1.4 \mathrm{MPa}\right)$, and even more strongly, becoming negative, under severe drought conditions $\left(\Psi_{\mathrm{L}}=-2.4 \mathrm{MPa}\right)$. At $40{ }^{\circ} \mathrm{C}, \mathrm{An}_{1500}$ decreased strongly (46\%) also at field capacity, and even more drastically $(93 \%)$ under mild drought conditions $\left(\Psi_{\mathrm{L}}=-1.4 \mathrm{MPa}\right)$. At $45^{\circ} \mathrm{C}$, only wellwatered plants had positive net photosynthesis, although with a reduction of $60 \%$. As net photosynthesis decreased with both temperature and drought, the intercellular $\mathrm{CO}_{2}$ concentration increased, both at increasing temperatures (for all drought levels) and at increasing levels of drought, except between
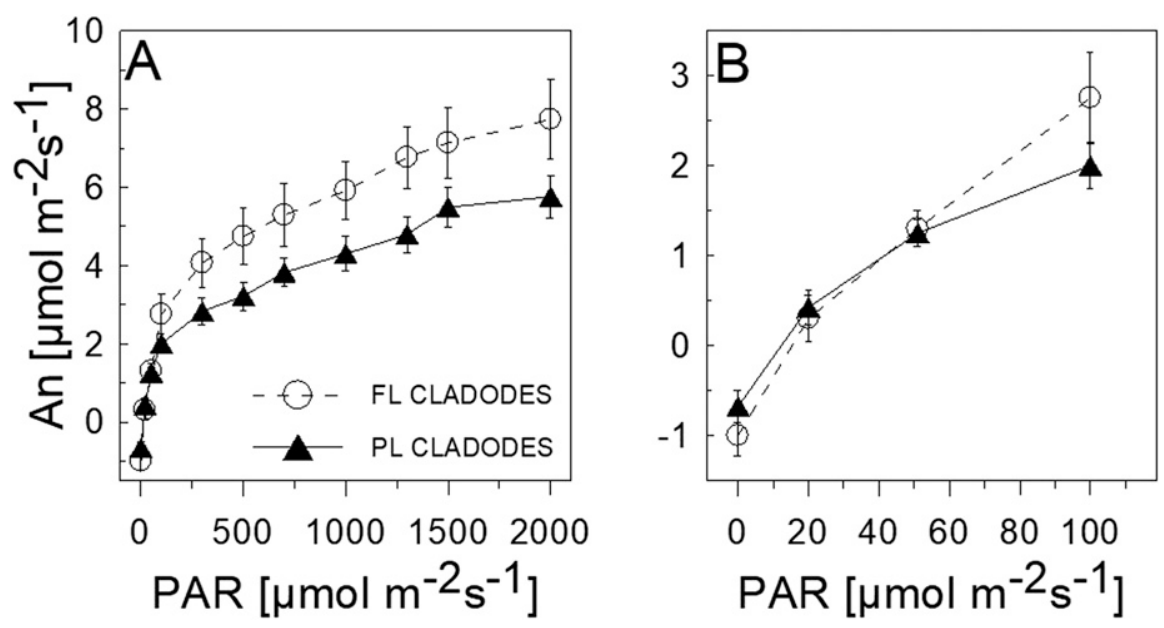

Fig. 2. (A) Net $\mathrm{CO}_{2}$ assimilation response (An) to photosynthetically active radiation (PAR) of Asparagus acutifolius cladodes from well-watered plants grown in full light (FL) or partial light (PL), measured at $20{ }^{\circ} \mathrm{C}$ (air temperature). Data from the new and old cladodes were pooled. Data represent mean and SE (bars) of 20 measurements. (B) Same data, but only for $P A R$ values from 0 to $100 \mu \mathrm{mol} \cdot \mathrm{m}^{-2} \cdot \mathrm{s}^{-1}$. lation was always negative as a result of high respiration, which is clearly connected to intense growth and metabolism of the young tissues (McCree, 1974). Also interesting is the fact that the subapical portion of the spear had less-negative net photosynthetic rates (Fig. 1A), despite having lower gross photosynthetic contributions (Fig. 1B), which is explained by the lower respiration, compared with the spear tips (Fig. 1A). In fact, in cultivated asparagus, high metabolism of the tip is proved by the rapid reduction of the sugars in the upward direction, from the stalk to the tip; below the tip there is the socalled elongation zone, where the cells are expanded and thickened and metabolism is reduced (Culpepper and Moon, 1939). In addition, the subapical zone is characterized by the rapid addition of cellulose and other structural materials, which may interfere with the photosynthetic activity (Edwards and Walker, 1983), explaining the lower contribution in this zone in terms of gross photosynthesis.

Photosynthetic characteristics of cladodes. Although photosynthesis of tips and trunks saturated at high irradiance (i.e., 1500 $\mu \mathrm{mol} \cdot \mathrm{m}^{-2} \cdot \mathrm{s}^{-1}$ ) (Fig. 1), as expected for a flat photosynthetic surface, the cladodes' lightresponse curve was not asymptotic. This is probably because the cladodes' net photosynthesis was measured on small branches with 40 to 70 cladodes, oriented in all directions, rather than measuring a flat surface such as a broad leaf. Therefore, the cladodes captured the direct light, the diffuse light, and the light reflected by the cuvette walls, as described for conifers (Carter and Smith, 1985). Also, the direct light (i.e., the majority under sunny conditions) was not perpendicular to most cladodes, making them unlikely to reach saturation (Sinclair et al., 1976). Unlike the cultivated species, the ferns of this wild asparagus are perennial, and the photosynthetic activity of previous and current-year ferns was comparable. This gives this species a great advantage over the cultivated asparagus, which, as a deciduous species, has no green vegetation from fall to spring and has to regrow all the canopy each year before it can be photosynthetically active. Having photosynthetically active ferns before and during the harvest of the spears, the spring storage depletion reported for the cultivated species (Haynes, 1987) should be reduced in the wild asparagus, although there is no literature available to prove this. In fact, during the winter, net $\mathrm{C}$ assimilation was positive down to $0{ }^{\circ} \mathrm{C}$ (Fig. 4A). Considering the Mediterranean habitat of the species, with mild winters, the plant appears to have the opportunity to produce and store reserves during the winter. The evergreen nature of the plant, combined

Table 1. Cladode morphologic characteristics in Asparagus acutifolius as affected by the light treatments full light (FL) and partial light (PL). ${ }^{\mathrm{B}}$

\begin{tabular}{lllccc}
\hline Treatment & Length $(\mathrm{mm})$ & Radius $(\mathrm{mm})$ & Lateral area $\left(\mathrm{mm}^{2}\right)$ & Volume $\left(\mathrm{mm}^{3}\right)$ & $\mathrm{Lateral} \mathrm{area}^{2}$ vol. $\left(\mathrm{mm}^{2} \cdot \mathrm{mm}^{-3}\right)$ \\
\hline FL & $4.26 \pm 0.30 \mathrm{~b}$ & $0.24 \pm 0.01 \mathrm{~b}$ & $6.44 \pm 0.56 \mathrm{~b}$ & $0.78 \pm 0.08 \mathrm{a}$ & $8.26 \pm 0.28 \mathrm{~b}$ \\
PL & $6.31 \pm 0.38 \mathrm{a}$ & $0.21 \pm 0.01 \mathrm{a}$ & $8.38 \pm 0.64 \mathrm{a}$ & $0.90 \pm 0.10 \mathrm{a}$ & $9.31 \pm 0.34 \mathrm{a}$ \\
\hline
\end{tabular}

${ }^{\mathrm{z}}$ Data are the means of 400 cladodes. Different letters indicate significant differences $(P \leq 0.05)$ between treatments. 
with the positive photosynthesis at low temperatures, appears to explain the plant's natural occurrence in woodlands and shrublands (Tutin, 1980); the plant can take advantage of the light available during the winter in deciduous forests. However, the plant appears just as adapted to take advantage of full-sun conditions, even in hot Mediterranean summers. In fact, photosynthesis was greater for plants grown in full light (Fig. 2A), except at extreme temperatures (Fig. 4A). This was related to different cladode morphology. FL plants had thicker and shorter cladodes, suggesting plasticity of the plant in adapting to varying light environments. Guo et al. (2002) compared two varieties of Asparagus officinalis and found that the higher yielding variety, which also had greater photosynthesis, presented thicker cladodes. They, supported by the results of previous investigations (Bai and Kelly 1999; Faville et al., 1999), attributed the greater $\mathrm{CO}_{2}$ assimilation activity

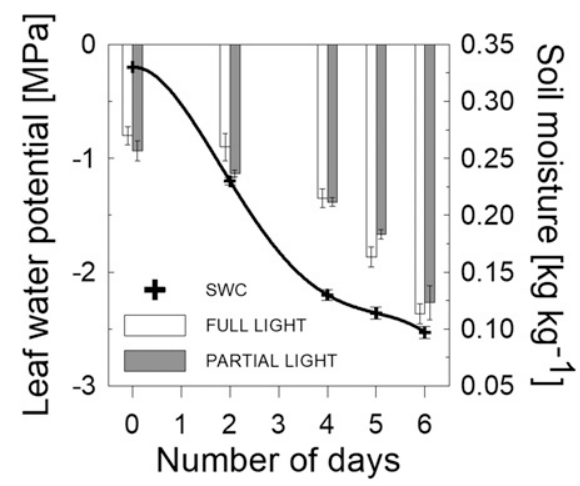

Fig. 3. Predawn leaf water potential and soil moisture variations in Asparagus acutifolius during the $6 \mathrm{~d}$ of the drought experiment. Data represent mean and SE (bars) of 10 measurements for soil water content (data pooled for the two light treatments) and of 15 measurements per treatment for leaf water potential.
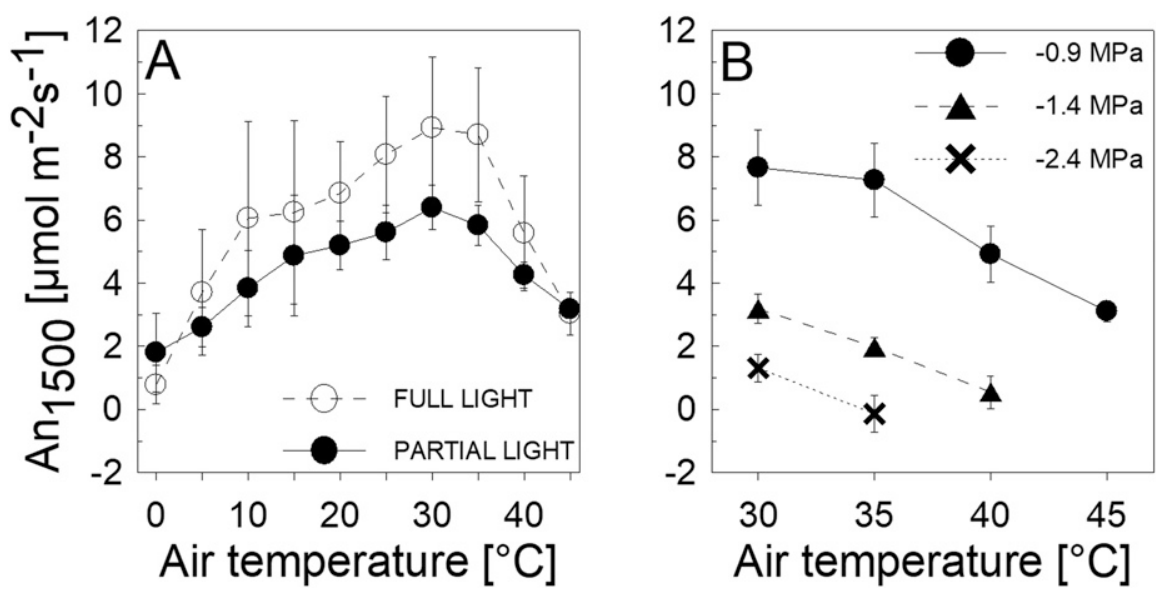

Fig. 4. (A) Response of net $\mathrm{CO}_{2}$ assimilation at $1500 \mu \mathrm{mol} \cdot \mathrm{m}^{-2} \cdot \mathrm{s}^{-2}$ of photosynthetically active radiation $\left(\mathrm{An}_{1500}\right)$ to varying air temperature in new cladodes from well-watered plants of Asparagus acutifolius grown in full light or partial light. Data represent mean and SE (bars) of five measurements. (B) Same data for well-watered plants, but pooling the two light treatments, and data for increasing drought levels (i.e., $\Psi 1$ of $-0.9,01.4$, and $-2.4 \mathrm{MPa}$ ) at increasing temperatures starting from $30^{\circ} \mathrm{C}$. Data represent mean and SE (bars) of 10 measurements per each temperature step. irreversible injury to the photosynthetic system (Berry and Bjorkman, 1980). However, eventually, heat stress leads to photoinhibition; consequently, a reduction in primary production is to be expected (Boyer, 1982; Larcher, 1995). Also, the decline of the photosynthetic rate with increasing water stress was quite moderate and became severe (83\%) only at $\Psi_{\mathrm{L}}$ values of $-2.4 \mathrm{MPa}$ (Fig. 4B), which are not tolerated by most plant species (Lambers et al., 2008). The reduction in photosynthetic rates at high temperatures and drought conditions did not appear to result from stomatal control, because the intercellular $\mathrm{CO}_{2}$ concentration always increased at both increasing temperatures and drought conditions(Fig. 5), and therefore it appeared to be the result of direct impacts on photosynthetic metabolism (Farquhar and Sharkey, 1982). The intertwined effect of heat and drought stress (Fig. 4B) suggests that irrigation may be a means to overcome or limit heat stress in high-temperature environments, whereas shade and the consequent cooling may help where irrigation is not available.

\section{Conclusions}

The wild asparagus species we studied appears to combine an assimilation ability comparable with that of the cultivated asparagus under optimal growing conditions, but also shows adaptability to shade, extremely low winter and high summer temperatures, and severe drought. Hence, this species shows great ecophysiologic plasticity. In a present and future scenario of climate change, with higher temperatures, more frequent droughts, and a more erratic climate, this wild asparagus represents an interesting crop able to withstand temperature extremes and droughts. In addition, under such scenarios, agroforestry systems combining trees and crops are believed to have the potential to both mitigate and provide adaptation to climate change. However, tree shade usually reduces crop production. This wild asparagus has the ability to adapt to shade and to avoid it, being an evergreen species with positive photosynthesis at low temperature, thus photosynthesizing in winter when deciduous trees allow good lighting of the understory layer. In addition, tree shade reduces leaf temperatures and this might reduce hightemperature stress and enhance photosynthesis under moderate shade in the summer, when temperature - and not light - is the limiting factor. All in all, Asparagus acutifolius could be a useful perennial species in challenging environments, both as a monocrop or as the understory layer in agroforestry systems designed for high resiliency and climate adaptation.

\section{Literature Cited}

Aliotta, G., S. Aceto, A. Farina, L. Gaudio, A. Rosati, M. Sica, and A. Parente. 2004. Natural history, cultivation and biodiversity assessment of asparagus. Res. Adv. Agr. Food Chem. 5:112. 
Bai, Y. and J.F. Kelly. 1999. A study of photosynthetic activities of eight asparagus genotypes under field condition. J. Amer. Soc. Hort. Sci. 124:61-66.

Benincasa, P., F. Tei, and A. Rosati. 2007. Plant density and genotype effects on wild asparagus (Asparagus acutifolius L.) spear yield and quality. HortScience 42:1163-1166.

Berry, J. and O. Bjorkman. 1980. Photosynthetic response and adaptation to temperature in higher plants. Annu. Rev. Plant Physiol. 31(1): 491-543.

Boyer, J.S. 1982. Plant productivity and environment. Science 218(4571):443-448.

Carter, G.A. and W.K. Smith. 1985. Influence of shoot structure on light interception and photosynthesis in conifers. Plant Physiol. 79(4): 1038-1043.

Conversa, G. and A. Elia. 2009. Effect of seed age, stratification, and soaking on germination of wild asparagus (Asparagus acutifolius L.). Scientia Hort. 119(3):241-245.

Culpepper, C.W. and H.H. Moon. 1939. Changes in the composition and rate of growth along the developing stem of asparagus. Plant Physiol. 14(4):677.

Di Maro, A., S. Pacifico, A. Fiorentino, S. Galasso, M. Gallicchio, V. Guida, V. Severino, P. Monaco, and A. Parente. 2013. Raviscanina wild asparagus (Asparagus acutifolius L.): A nutritionally valuable crop with antioxidant and antiproliferative properties. Food Res. Intl. 53(1):180-188.

Downton, W.J.S. and E. Torokfalvy. 1975. Photosynthesis in developing asparagus plants. Funct. Plant Biol. 2(3):367-375.

Dupraz, C., G.J. Lawson, N. Lamersdorf, V.P. Papanastasis, A. Rosati, and J. Ruiz-Mirazo. 2018. Temperate agroforestry: The European way, p. 98-152. In: A.M. Gordon, S.M. Newman, and B. Coleman (eds.). Temperate agroforestry systems. CABI, Wallingford, UK.

Edwards, G.E. and D.A. Walker. 1983. C3, C4: Mechanisms, cellular and environmental regulation of photosynthesis. University of California Press, Berkeley, CA.

Farquhar, G.D. and T.D. Sharkey. 1982. Stomatal conductance and photosynthesis. Annu. Rev. Plant Physiol. 33(1):317-345.

Faville, M.J., W.B. Silvester, T.G. Green, and W.A. Jermyn. 1999. Photosynthetic characteristics of three asparagus cultivars differing in yield. Crop Sci. 39(4):1070-1077.

Ferrara, L., R. Dosi, A. Di Maro, V. Guida, G. Cefarelli, S. Pacifico, C. Mastellone, A. Fiorentino, A. Rosati, and A. Parente. 2011. Nutritional values, metabolic profile and radical scavenging capacities of wild asparagus (Asparagus acutifolius L.). J. Food Compos. Anal. 24:326333.

Guo, J., W.A. Jermyn, and M.H. Turnbull. 2002. Diurnal and seasonal photosynthesis in two asparagus cultivars with contrasting yield. Crop Sci. 42(2):399-405.

Haynes, R.J. 1987. Accumulation of dry matter and changes in storage carbohydrate and amino acid content in the first 2 years of asparagus growth. Scientia Hort. 32(1-2):17-23.

Hills, M.J. 1986. Photosynthetic characteristics of mesophyll cells isolated from cladophylls of Asparagus officinalis L. Planta 169(1):38-45.

Lambers, H., F.S. Chapin, III, and T.L. Pons. 2008. Plant water relations, p. 163-223. In: H. Lambers (ed.). Plant physiological ecology. Sprinter, New York, NY.

Larcher, W. 1995. Photosynthesis as a tool for indicating temperature stress events, p. 261277. In: E.D. Schulze and M. M. Caldwell (ed.). Ecophysiology of photosynthesis. Springer, Berlin, Germany.

Mantovani, D., M. Veste, and D. Freese. 2014a. Black locust (Robinia pseudoacacia L.) ecophysiological and morphological adaptations to drought and their consequence on biomass production and water-use efficiency. N. Z. J. For. Sci. 44(1):1-11.

Mantovani, D., M. Veste, S. Gypser, C. Halke, L. Koning, and D. Freese. 2014b. Transpiration and biomass production of the bio-energy crop giant knotweed IGNISCUM under different water and nutrient supply. J. Hydrol. Hydromech. 62:316-323.

McCree, K.J. 1974. Equations for the rate of dark respiration of white clover and grain sorghum, as functions of dry weight, photosynthetic rate, and temperature. Crop Sci. 14(4):509-514.

Pansu, M. and J. Gautheyrou. 2007. Handbook of soil analysis: Mineralogical, organic and inorganic methods. Springer, Germany.

Paris, P., F. Camilli, A. Rosati, A. Mantino, G. Mezzalira, C. Dalla Valle, A. Franca, G Seddaiu, A. Pisanelli, M. Lauteri, A. Brunori, G.A. Re, F. Sanna, G. Ragaglini, M. Mele, V. Ferrario, and P.J. Burgess. 2019. What is the future for agroforestry in Italy? Agrofor. Syst., doi: 10.1007/s10457-019-00346-y.

Pearcy, R.W., J.R. Ehleringer, H. Mooney, and P.W. Rundel. 2012. Plant physiological ecology: Field methods and instrumentation. Springer, Germany.

Pieroni, A., S. Nebel, R.F. Santoro, and M. Heinrich. 2005. Food for two seasons: Culinary uses of non-cultivated local vegetables and mushrooms in a south Italian village. Intl. J. Food Sci. Nutr. 56(4):245-272.

R Development Core Team. 2014. R: A language and environment for statistical computing. R Foundation for Statistical Computing, Vienna, Austria. <http://www.R-project.org/>.

Rosati, A. 2001. Un possibile futuro per l'asparago selvatico. Inf. Agrar. 7(57):89-92.

Rosati, A., S. Caporali, and A. Paoletti. 2009. Olive, asparagus and animals: an agroforestry model for temperate climate in developed countries. Proceedings of the III OLIVEBIOTEQ (For a renovated, profitable and competitive Mediterranean olive growing sector), Sfax, Tunisia, 15-19 Dec. 2009, ISBN: 9789938-9513-0-1, 229-233.

Rosati, A., K.R. Day, and T.M. Dejong. 2000. Distribution of leaf mass per unit area and leaf nitrogen concentration determine partitioning of leaf nitrogen within peach tree canopies. Tree Physiol. 20:271-276.

Rosati, A., G. Esparza, T.M. Dejong, and R.W Pearcy. 1999. Influence of canopy light environment and nitrogen availability on leaf photosynthetic characteristics and photosynthetic nitrogen-use efficiency of field-grown nectarine trees. Tree Physiol. 19:173-180.

Rosati, A. and A. Falavigna. 2000. Germinazione dei semi di asparago selvatico. Inf. Agrar. 46(56):53-55.

Rosati, A., R. Pepe, A. Senatore, D. Perrone, and A. Falavigna. 2005. Produttività dell'asparago selvatico. Inf. Agrar. 8(61):75-77.

Scholander, P.F., E.D. Bradstreet, E.A. Hemmingsen, and H.T. Hammel. 1965. Sap pressure in vascular plants: Negative hydrostatic pressure can be measured in plants. Science 148(3668): 339-346.

Sinclair, T.R., C.E. Murphy, and K.R. Knoerr. 1976. Development and evaluation of simplified models for simulating canopy photosynthesis and transpiration. J. Appl. Ecol. 13:813-829.

Tutin, T.G. 1980. Flora europaea. Vol. 5. Cambridge University Press, Cambridge, UK.

Veste, M. and W.U. Kriebitzsch. 2013. Influence of drought stress on photosynthesis, transpiration, and growth of juvenile black locust (Robinia pseudoacacia L.). Forstarchiv 84(2): 35-42.

Wahid, A. 2007. Physiological implications of metabolite biosynthesis for net assimilation and heat-stress tolerance of sugarcane (Saccharum officinarum) sprouts. J. Plant Res. 120(2): 219-228. 